\title{
Phylogenetic Position of Shiraia-Like Endophytes on Bamboos and the Diverse Biosynthesis of Hypocrellin and Hypocrellin Derivatives
}

\author{
Xin Tong ${ }^{1}$, Qiu-Tong Wang ${ }^{1}{ }^{\circledR}$, Xiao-Ye Shen ${ }^{1, *}$, Cheng-Lin Hou ${ }^{1, *}$ and Paul F. Cannon ${ }^{2}$ \\ 1 College of Life Science, Capital Normal University, Xisanhuanbeilu 105, Haidian, Beijing 100048, China; \\ tongxin1112@126.com (X.T.); 2190801014@cnu.edu.cn (Q.-T.W.) \\ 2 Royal Botanic Gardens, Kew, Surrey TW9 3AB, UK; p.cannon@kew.org \\ * Correspondence: shenxiaoye2009@cnu.edu.cn (X.-Y.S.); houchenglincn@yahoo.com (C.-L.H.)
}

Citation: Tong, X.; Wang, Q.-T.; Shen, X.-Y.; Hou, C.-L.; Cannon, P.F. Phylogenetic Position of Shiraia-Like Endophytes on Bamboos and the Diverse Biosynthesis of Hypocrellin and Hypocrellin Derivatives. J. Fungi 2021, 7, 563. https://doi.org/ 10.3390/jof7070563

Academic Editor: Pradeep K. Divakar

Received: 29 May 2021

Accepted: 5 July 2021

Published: 14 July 2021

Publisher's Note: MDPI stays neutral with regard to jurisdictional claims in published maps and institutional affiliations.

Copyright: (c) 2021 by the authors. Licensee MDPI, Basel, Switzerland. This article is an open access article distributed under the terms and conditions of the Creative Commons Attribution (CC BY) license (https:// creativecommons.org/licenses/by/ $4.0 /)$.

\begin{abstract}
The main active ingredients of the fruiting bodies of Shiraia bambusicola and Rubroshiraia bambusae are Hypocrellins, belonging perylenequinones with potential photodynamic activity against cancer and microbial diseases. However, the strains of S. bambusicola and R. bambusae do not produce hypocrellins in culture, so resource exploitation of natural products was seriously restricted. In this study, a series of novel Shiraia-like fungal endophyte strains, with varying sporulation ability and synthesizing diverse secondary metabolites, was isolated from different bamboos. Based on phylogenetic analyses and morphological characteristics of the endophytes, Pseudoshiraia conidialis gen. et sp. nov. is proposed. The secondary metabolites of different fruiting bodies and strains have been comprehensively analyzed for the first time, finding that the endophytic strains are shown not only to produce hypocrellins, but also other perylenequinonoid compounds. It was noteworthy that the highest yield of total perylenequinone production and hypocrellin A appeared in P. conidialis CNUCC 1353PR (1410.13 mg/L), which was significantly higher than any other wild type P. conidialis strains in published reports. In view of these results, the identification of Shiraia-like endophytes not only confirm the phylogenetic status of similar strains, but will further assist in developing the production of valuable natural products.
\end{abstract}

Keywords: shiraiaceae; endophyte; morphology; secondary metabolites; new taxa

\section{Introduction}

Hypocrellins belong to the perylenequinonoid family of compounds. They are very important photosensitizers and have attracted broad attention because of their light-induced antitumour, antifungal and antiviral activities [1-7]. In China, hypocrellins have been used medicinally to treat skin diseases for many years [8]. In recent years, hypocrellins and their derivatives have been incorporated into polymer micelles or nanoparticles for the treatment of methicillin-resistant Staphylococcus aureus infections [9] and cancer therapy [10-12]. In addition to benefiting the pharmaceutical industry, hypocrellins also have extensive potential applications in the agricultural, cosmetic, food and feed industries [13-15].

The hypocrellin cluster consists of five main compounds-hypocrellin (1), hypocrellin A (2), hypocrellin B (3), shiraiachrome A (4), and hypocrellin D (5), and their structures are shown in Figure 1. There is some confusion in the literature over the nomenclature of these compounds, and in this paper the names as defined by $\mathrm{Al}$ Subeh et al. are followed [16]. Hypocrellin (1), hypocrellin A (2) and hypocrellin B (3) were first isolated from traditional Chinese medicinal products, which were called "Zhuhongjun" or "Zhuxiaorouzuojun" [1,17-19], and were identified as Hypocrella bambusae (Berk. \& Broome) Sacc. by Liu [20]. Subsequent studies reported that extracts of ascostromata of Shiraia bambusicola Henn. also contained hypocrellin A (2) and hypocrellin B (3), as well as shiraiachrome A (4) and hypocrellin D (5) [21-23]. 


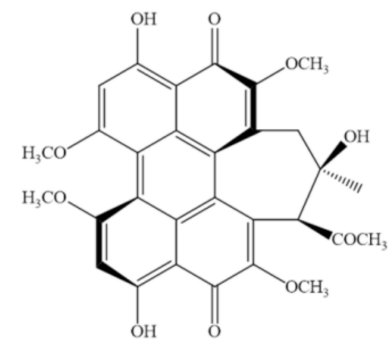

1

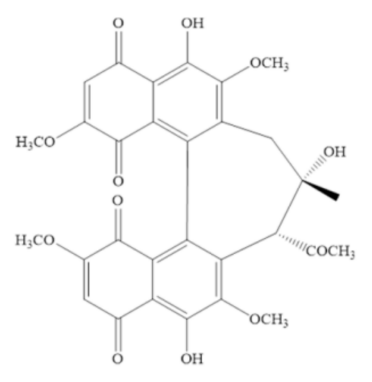

5

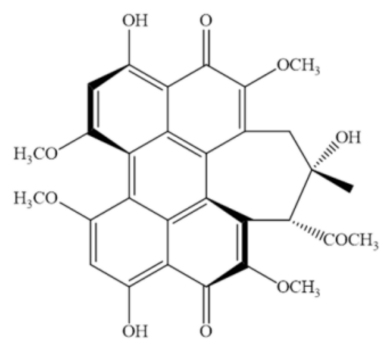

2

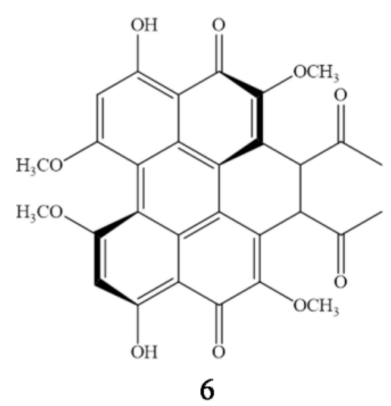

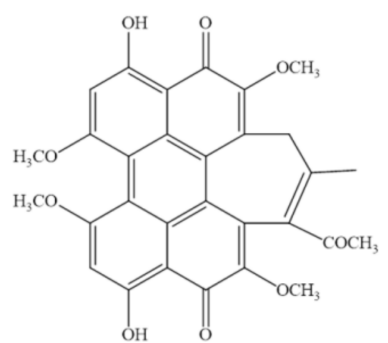

3

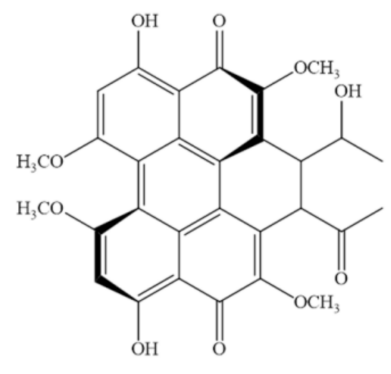

7

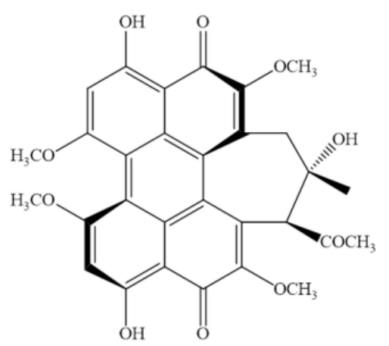

4

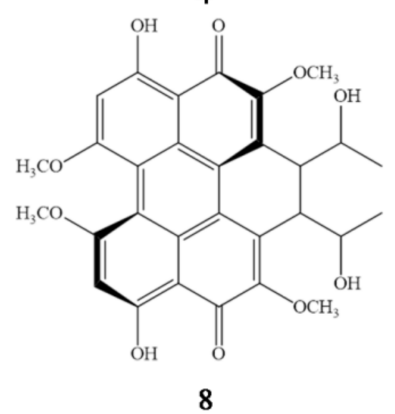

Figure 1. Chemical structures of hypocrellin (1), hypocrellin A (2), hypocrellin B (3), shiraiachrome A (4), hypocrellin D (5), elsinochrome A (6), elsinochrome B (7) and elsinochrome C (8).

However, the taxonomic status of hypocrellin producing species remained confused. Liu et al. introduced the family Shiraiaceae (Pleosporales) Y.X. Liu, Zi Y. Liu \& K.D. Hyde to accommodate genus Shiraia Henn [24]. More recently, Dai et al. described a new genus Rubroshiraia D.Q. Dai \& K.D. Hyde in Shiraiaceae based on morphological characteristics and phylogenetic analysis, and concluded that the traditional Chinese medicine which was called "Zhuhongjun" or "Zhuxiaorouzuojun" in Chinese should be assigned to the new species R. bambusae D.Q. Dai \& K.D. Hyde rather than the unrelated Hypocrella bambusae (Berk. \& Broome) Sacc [25].

Shiraia-like endophytes associated with plants have been identified and shown to produce hypocrellins [16,26-29]. Based on phylogenetic analysis, these strains generally clustered in the family Shiraiaceae $[25,26]$, but their explicit taxonomic status could not be established due to the lack of morphological characteristics.

Since 2008, we have been characterizing Shiraia-like endophytes from bamboos, and have explored several interesting strains with conidial production, and diverse natural products. The aim of this study is to accurately establish the taxonomic status of Shiraialike endophytes based on morphological characteristics and phylogenetic analysis, and comprehensively analyze the secondary metabolites of these strains.

\section{Materials and Methods}

\subsection{Isolates}

Fruit bodies of Shiraia bambusicola were collected from Hangzhou, Zhejiang, China and those of Rubroshiraia bambusae from Yulong County, Yunnan, China. Fungal endophytes were isolated from asymptomatic tissues of bamboos (Poaceae: Bambusoideae) in various localities in China (Table 1). The methods of isolation are described in Shen et al. [30] and Zhou et al. [31]. All isolates were cultured on Potato Dextrose Agar (PDA, containing $200 \mathrm{~g} / \mathrm{L}$ potato, $20 \mathrm{~g} / \mathrm{L}$ dextrose and $20 \mathrm{~g} / \mathrm{L}$ agar) at $25{ }^{\circ} \mathrm{C}$ for 14 days to observe the morphology. The specimens were deposited in the Fungarium of the College of Life Science, Capital Normal University, Beijing, China (BJTC) and the China Forest Biodiversity Museum of the Chinese Academy of Forestry (CAF), and ex-type living cultures were deposited in the China Forestry Culture Collection Center (CFCC) and Capital Normal University Culture Collection Center (CNUCC). 
Table 1. GenBank accession numbers of isolates used for phylogenetic construction.

\begin{tabular}{|c|c|c|c|c|c|c|c|}
\hline \multirow{2}{*}{ Species } & \multirow{2}{*}{ Specimen Voucher } & \multirow{2}{*}{ Location } & \multicolumn{5}{|c|}{ GenBank Accession Numbers } \\
\hline & & & ITS & LSU & SSU & TEF & RPB2 \\
\hline Didymocyrtis banksiae & CBS $142523 *$ & Australia & KY979757 & KY979812 & - & - & KY979850 \\
\hline \multirow[t]{2}{*}{ Neoshiraia camelliae } & NTUCC 18-092-1 * & China, Taiwan & MT112286 & MT071262 & МТ071213 & MT743267 & MT513982 \\
\hline & NTUCC 18-092-2 & China, Taiwan & MT112287 & MT071263 & MT071214 & MT743268 & MT513981 \\
\hline \multirow[t]{4}{*}{ Neoshiraia taiwanensis } & NTUCC $17-031$ * & China, Taiwan & MT112285 & MT071261 & MT071212 & MT114404 & MT743276 \\
\hline & NTUCC 18-091-5 & China, Taiwan & MT112280 & MT150600 & MT071207 & MT114405 & MT434762 \\
\hline & NTUCC 18-091-6 & China, Taiwan & MT112309 & MT150602 & MT071236 & MT425440 & MT434766 \\
\hline & NTUCC 18-091-7 & China, Taiwan & MT112310 & MT150601 & MT071237 & MT425441 & MT434765 \\
\hline $\begin{array}{c}\text { Phaeosphaeria } \\
\text { chiangraina }\end{array}$ & MFLUCC 13-0231 * & Thailand & KM434270 & KM434280 & KM434289 & KM434298 & KM434307 \\
\hline Phaeosphaeria oryzae & CBS 110110 * & South Korea & KF251186 & KF251689 & GQ387530 & - & KF252193 \\
\hline Phaeosphaeria sp. & 20081120 & China, Yunnan & HQ324780 & - & - & - & - \\
\hline Pleospora herbarum & CBS $191.86^{*}$ & India & KC584239 & DQ247804 & GU238232 & DQ471090 & DQ247794 \\
\hline Pleosporales sp. & MX286 & - & JQ905814 & - & - & - & - \\
\hline $\begin{array}{l}\text { Phaeosphaeriopsis } \\
\text { agavacearum }\end{array}$ & СРC $29122 *$ & Australia & KY173430 & KY173520 & - & - & KY173591 \\
\hline Poaceicola italica & MFLUCC 13-0267 & Italy & KX926421 & KX910094 & KX950409 & MG520924 & KX891169 \\
\hline $\begin{array}{l}\text { Populocrescentia } \\
\text { forlicesesensis }\end{array}$ & MFLU 15-0651* & - & КТ306948 & КT306952 & КT306955 & MG520925 & - \\
\hline \multirow[t]{15}{*}{ Pseudoshiraia conidialis } & zzz816 & China, Guangxi & HQ696072 & MZ519516 & HQ696106 & MZ516164 & MZ516177 \\
\hline & zzz510 & China, Guangxi & HQ696078 & MZ519517 & MZ519540 & MZ516165 & - \\
\hline & CNUCC 0316 & China, Guangxi & MZ519529 & MZ519521 & MZ519536 & - & - \\
\hline & CNUCC 0334 & China, Guangxi & MZ519528 & MZ519520 & MZ519535 & MZ516160 & - \\
\hline & CNUCC 0019 & China, Guangxi & MZ519532 & MZ519523 & MZ519538 & MZ516162 & - \\
\hline & CNUCC 0164 & China, Guangxi & MZ519530 & MZ519522 & MZ519537 & MZ516161 & MZ516175 \\
\hline & CNUCC 1353PR * & China, Yunnan & MZ519527 & MZ519534 & MZ519533 & MZ516168 & - \\
\hline & CNUCC 0006 & China, Anhui & MZ519531 & MZ519524 & MZ519539 & MZ516163 & MZ516176 \\
\hline & JAP103846 & Japan & MZ519526 & MZ519519 & MZ519542 & MZ516167 & MZ516179 \\
\hline & JAP103847 & Japan & MZ519525 & MZ519518 & MZ519541 & MZ516166 & MZ516178 \\
\hline & JP93 & Japan & AB255277 & AB354975 & - & - & - \\
\hline & JP256 & Japan & AB354995 & AB354980 & - & - & - \\
\hline & JP232 & Japan & AB255303 & AB354979 & - & - & - \\
\hline & JP7 & Japan & AB255241 & AB354974 & - & - & - \\
\hline & SUPER H168 & China & EU267793 & - & EU267792 & - & - \\
\hline \multirow[t]{9}{*}{ Rubroshiraia bambusae } & HKAS102255 * & China & MK804678 & MK804658 & MK804704 & MK819218 & - \\
\hline & HKAS102256 & China & MK804679 & MK804659 & MK804705 & MK819219 & - \\
\hline & HKAS102260 & China & MK804680 & MK804660 & MK804706 & MK819220 & - \\
\hline & HKAS102268 & China & MK804681 & MK804661 & MK804707 & MK819221 & - \\
\hline & HKAS102269 & China & MK804682 & MK804662 & MK804708 & MK819222 & - \\
\hline & HKAS102270 & China & MK804683 & MK804663 & MK804709 & MK819223 & - \\
\hline & HKAS102271 & China & MK804684 & MK804664 & MK804710 & MK819224 & - \\
\hline & HKAS102272 & China & MK804685 & MK804665 & MK804711 & MK819225 & - \\
\hline & HKAS102273 & China & MK804686 & MK804666 & MK804712 & MK819226 & - \\
\hline
\end{tabular}


Table 1. Cont.

\begin{tabular}{|c|c|c|c|c|c|c|c|}
\hline \multirow{2}{*}{ Species } & \multirow{2}{*}{ Specimen Voucher } & \multirow{2}{*}{ Location } & \multicolumn{5}{|c|}{ GenBank Accession Numbers } \\
\hline & & & ITS & LSU & SSU & TEF & RPB2 \\
\hline & HKAS102274 & China & MK804687 & MK804667 & MK804713 & MK819227 & - \\
\hline & BJTC HOU1000 & China, Yunnan & MZ497359 & MZ497374 & MZ497385 & MZ516169 & - \\
\hline & CNUCC 1000 & China, Yunnan & MZ497360 & MZ497376 & MZ497387 & MZ516170 & MZ516180 \\
\hline Sclerostagonospora ericae & СРC $25927^{*}$ & South Africa & KX228268 & KX228319 & - & - & - \\
\hline \multirow[t]{21}{*}{ Shiraia bambusicola } & HKAS102253 & China & MK804668 & MK804648 & MK804694 & MK819208 & MK819228 \\
\hline & HKAS102254 & China & MK804669 & MK804649 & MK804695 & MK819209 & MK819229 \\
\hline & HKAS102257 & China & MK804670 & MK804650 & MK804696 & MK819210 & MK819230 \\
\hline & HKAS102261 & China & MK804671 & MK804651 & MK804697 & MK819211 & MK819231 \\
\hline & HKAS102262 & China & MK804672 & MK804652 & MK804698 & MK819212 & MK819232 \\
\hline & HKAS102263 & China & MK804673 & MK804653 & MK804699 & MK819213 & MK819233 \\
\hline & HKAS102264 & China & MK804674 & MK804654 & MK804700 & MK819214 & MK819234 \\
\hline & HKAS102265 & China & MK804675 & MK804655 & MK804701 & MK819215 & MK819235 \\
\hline & HKAS102266 & China & MK804676 & MK804656 & MK804702 & MK819216 & MK819236 \\
\hline & HKAS102267 & China & MK804677 & MK804657 & MK804703 & MK819217 & MK819237 \\
\hline & NBRC 30312 & Japan & AB354982 & AB354963 & & & \\
\hline & NBRC 30147 & Japan & AB354981 & AB354962 & & & \\
\hline & NBRC 30737 & Japan & AB354983 & AB354964 & & & \\
\hline & GZAAS2.0709 & China & GQ845413 & KC460983 & - & - & - \\
\hline & GZAAS2.0629 & China & GQ845415 & КC460980 & - & - & - \\
\hline & GZAAS2.0703 & China & GQ845412 & KC460981 & - & - & - \\
\hline & GZAAS2.0708 * & China & GQ845414 & KC460982 & - & - & - \\
\hline & BJTC HOU999 & China, Zhejiang & MZ497363 & MZ497378 & MZ497389 & MZ516171 & - \\
\hline & CNUCC 122 & China, Zhejiang & MZ497367 & MZ497382 & MZ497391 & MZ516174 & - \\
\hline & CNUCC 172 & China, Zhejiang & MZ497366 & MZ497381 & MZ497390 & MZ516173 & - \\
\hline & CNUCC MJ1 & China, Zhejiang & MZ497365 & MZ497380 & MZ497392 & MZ516172 & - \\
\hline \multirow[t]{5}{*}{ Shiraia sp. } & JP151 & Japan & AB255289 & AB354977 & - & - & - \\
\hline & JP119 & Japan & AB354993 & AB354976 & - & - & - \\
\hline & JP185 & Japan & AB354994 & AB354978 & - & - & - \\
\hline & MSX60519 & - & MN970609 & - & - & - & - \\
\hline & slf14 & - & GQ355934 & - & HМ049630 & - & - \\
\hline
\end{tabular}

"-" indicating data unavailable. The strains of new species in this study are emphasized in bold. * Ex-holotype or ex-epitype cultures.

\subsection{Morphological Analysis}

Measurements and photographs of characteristic structures were made according to methods described by Liu et al. [32], and for each structure 30 measurements were made. Microscopic preparations were made in clear $\mathrm{H}_{2} \mathrm{O}$, observed and photographed using a Nikon SMZ-1000 dissecting microscope (DM), an OLYMPUS light microscope (LM) or a Hitachi S-4800 scanning electron microscope (SEM). Colony characters and pigment production on PDA incubated at room temperature were noted after $14 \mathrm{~d}$. Colony colors were taken from ColorHexa (https://www.colorhexa.com/, accessed on 18 December 2020). Growth rates were measured after 7 and $14 \mathrm{~d}$. 


\subsection{DNA Extraction, PCR Amplification and Sequencing}

Genomic DNA extraction was conducted according to Shen et al. [30]. Five loci including the $5.8 \mathrm{~S}$ nuclear ribosomal gene with the two flanking internal transcribed spacers (ITS), the large subunit rDNA (LSU), the small subunit rDNA (SSU), the translation elongation factor 1- $\alpha$ gene region (TEF1) and the RNA polymerase II second largest subunit (RPB2) were amplified and sequenced using the primer pairs ITSIF [33] + ITS4 [34], LR0R + LR5 [35], NS1 + NS4 [34], EF1-983F + EF1-2218R [36] and fRPB2-5f and fRPB2-7cr primers [37], respectively. The PCR mixture ( $25 \mu \mathrm{L}$, total volume) contained $2 \mu \mathrm{L}$ template, $1 \mu \mathrm{L}$ of each primer (10 mM each), $12.5 \mu \mathrm{L} 2 \times$ M5 HiPer Taq PCR mix (Mei5Bio, Beijing, China) and $8.5 \mu \mathrm{L} \mathrm{ddH_{2 }}$ O. The PCR amplification protocols are given in Table 2. The purified PCR products were sequenced by Zhongkexilin Biotechnology Co., Ltd. (Beijing, China).

Table 2. PCR amplification protocols of this study.

\begin{tabular}{|c|c|c|c|c|c|c|}
\hline Primer Pairs & $\begin{array}{c}\text { Initial Step } \\
(T, t)\end{array}$ & $\begin{array}{l}\text { Denaturation } \\
(T, t)\end{array}$ & $\begin{array}{l}\text { Annealing } \\
\quad(T, t)\end{array}$ & $\begin{array}{l}\text { Elongation } \\
\quad(T, t)\end{array}$ & Cycles & $\begin{array}{l}\text { Final Step } \\
\quad(T, t)\end{array}$ \\
\hline ITSIF/ITS4 & & & $55^{\circ} \mathrm{C}, 30 \mathrm{~s}$ & $72{ }^{\circ} \mathrm{C}, 45 \mathrm{~s}$ & & \\
\hline LR0R/LR5 & & & $55^{\circ} \mathrm{C}, 30 \mathrm{~s}$ & $72^{\circ} \mathrm{C}, 90 \mathrm{~s}$ & & \\
\hline NS1/NS4 & $94^{\circ} \mathrm{C}, 5 \mathrm{~min}$ & $94^{\circ} \mathrm{C}, 30 \mathrm{~s}$ & $52{ }^{\circ} \mathrm{C}, 30 \mathrm{~s}$ & $72{ }^{\circ} \mathrm{C}, 90 \mathrm{~s}$ & 35 & $72{ }^{\circ} \mathrm{C}, 10 \mathrm{~min}$ \\
\hline EF1-983F/EF1-2218R & & & $55^{\circ} \mathrm{C}, 30 \mathrm{~s}$ & $72{ }^{\circ} \mathrm{C}, 60 \mathrm{~s}$ & & \\
\hline fRPB2-5f/fRPB2-7cr & & & $50{ }^{\circ} \mathrm{C}, 30 \mathrm{~s}$ & $72{ }^{\circ} \mathrm{C}, 80 \mathrm{~s}$ & & \\
\hline
\end{tabular}

\subsection{Phylogenetic Analysis}

The new sequences were submitted to the GenBank database and other sequences included in this study were downloaded from GenBank (Table 1) based on recent publications $[25,38]$. The DNA sequences generated with forward and reverse primers were aligned to obtain consensus sequences using EditSeq version 5.00. A partition homogeneity test was done to determine the congruence of gene fragments $[39,40]$. Subsequent alignments were generated using online MAFFT tools (https://www.ebi.ac.uk/ Tools/msa/mafft/, accessed on 24 November 2020), and edited using Gblocks 0.91b (http:/ / www.phylogeny.fr/one_task.cgi?task_type=gblocks, accessed on 24 November 2020), selecting all options for a less stringent selection.

Maximum parsimony (MP) analysis was performed on the multi-locus alignment including two loci (ITS and LSU) with PAUP v.4.0b10 [41], using the heuristic search option with tree bisection and reconstruction (TBR) branch swapping and 1000 random sequence additions. Maxtrees were 1000, branches of zero length were collapsed and all multiple parsimonious trees were saved. Clade stability was assessed in a bootstrap analysis with 1000 replicates, each with 10 replicates of random stepwise addition of taxa. Tree statistics (TL), consistency index (CI), retention index (RI), rescaled consistency index (RC) and homoplasy index (HI) as the descriptive tree statistics were calculated for the generated trees.

For the Bayesian analysis, a Markov Chain Monte Carlo (MCMC) algorithm was conducted to reconstruct the single locus and multi-locus phylogenetic trees with Bayesian posterior probabilities in MrBayes v. 3.1.1 [42]. For the Bayesian analysis, models of nucleotide substitution were determined by MrModeltest v.2.3 [43] for each gene and included in the analyses (ITS, LSU, TEF and TUB2: GTR + I + G, SSU: HKY + I). The analyses of four chains were conducted for 10,000,000 generations with the default settings and sampled every 100 generations, halting the analyses at the average standard deviation of split frequencies of 0.01 . The first $25 \%$ trees were discarded as the burn-in phase of the analyses and the posterior probabilities (PP) were obtained from the remaining trees.

Maximum likelihood (ML) analysis of the dataset was carried out using RAxML 8.0.14 [44-46] and the GTRGAMMI substitution model with parameters unlinked. The ML bootstrap replicates (1000) were computed in RAxML using a rapid bootstrap analysis and search for the best-scoring ML tree. 
Trees were viewed in Treeview [47] and edited in Coreldraw v.X4 (Corel Corporation, Canada). ML bootstrap values (MLBS) and MP bootstrap values (MPBP) equal to or greater than $50 \%$ and Bayesian posterior probability (PP) equal to or greater than 0.95 are given at each node (Figure 2). The combined alignment and phylogenetic tree were submitted at TreeBASE (www.treebase.org, accessed on 24 November 2020; study S28492).

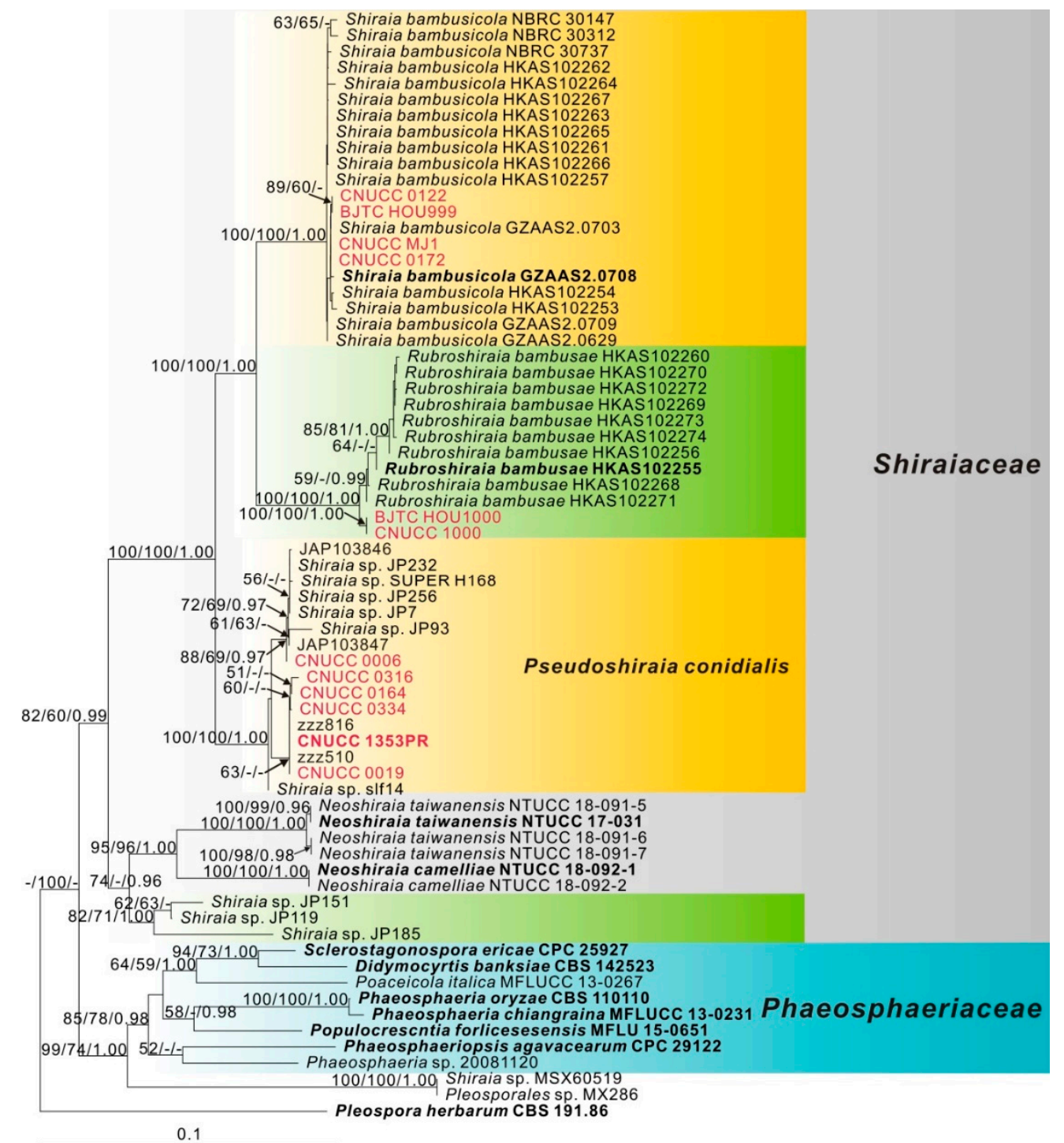

Figure 2. The phylogenetic tree based on the concatenated alignment of four molecular markers (ITS, LSU, SSU, TEF and RPB2) evaluated using RAxML. The new isolates are shown in red. Numbers of ex-holotype or ex-epitype strains are emphasized in bold. ML bootstrap values (MLBS) $\geq 50 \%$, MP bootstrap values (MPBS) $\geq 50 \%$ and Bayesian posterior probabilities (PP) $\geq 0.95$ are at each node. The scale bar indicates the number of estimated substitutions per site. Pleospora herbarum (CBS 191.86) was used as outgroup for rooting the tree.

\subsection{Submerged Cultivation and Secondary Metabolite Extraction}

The endophytic fungi isolates were cultured on PDA at $26^{\circ} \mathrm{C}$ for 7 days. Based on colony colour, three strains representing different morphs were selected for further experiments. Five plugs ( $5 \mathrm{~mm}$ in diameter) of growing culture plus the adhering mycelium were added to $250 \mathrm{~mL}$ Erlenmeyer flasks containing $150 \mathrm{~mL}$ of Potato Dextrose Broth media (PDB, containing $200 \mathrm{~g} / \mathrm{L}$ potato and $20 \mathrm{~g} / \mathrm{L}$ dextrose). All liquid cultures were kept at $26{ }^{\circ} \mathrm{C}$ for $10 \mathrm{~d}$ with shaking (180 rpm). 
Fresh mycelia of the fungal strains Shiraia bambusicola CNUCC 0172, CNUCC 0122 and CNUCC MJ1 were cultured on PDA at $26^{\circ} \mathrm{C}$ for 10 days. Five plugs ( $5 \mathrm{~mm}$ in diameter) of growing culture plus the adhering mycelium were subsequently added to $150 \mathrm{~mL}$ PDB. The liquid cultures were kept at $26^{\circ} \mathrm{C}$ for $10 \mathrm{~d}$ with shaking (180 rpm).

Fresh mycelia of the fungal strain Rubroshiraia bambusae CNUCC 1000 were cultured on PDA at $16^{\circ} \mathrm{C}$ for 30 days. Five plugs ( $5 \mathrm{~mm}$ in diameter) of growing culture plus the adhering mycelium were subsequently added to $150 \mathrm{~mL}$ PDB. The liquid cultures were kept at $16^{\circ} \mathrm{C}$ for $40 \mathrm{~d}$ with shaking $(180 \mathrm{rpm})$.

The fermented mycelia of each fungus were filtered and dried at $45{ }^{\circ} \mathrm{C}$. The dry powder $(0.1 \mathrm{~g})$ of ascostromata and mycelia of S. bambusicola and R. bambusae was accurately weighed and ultrasonic extracted for $30 \mathrm{~min}$ with $5 \mathrm{~mL}$ methanol. The dry powder of endophytic mycelia was treated in the same manner.

\subsection{HPLC-DAD-MS Analysis}

HPLC-DAD-MS analysis was performed using a Shimadzu LC-20AD liquid chromatography (LC) system coupled with a diode array detector (DAD) and an electrospray ionization-ion-trap-time-of-flight (ESI-IT-TOF) mass spectrometer (MS) (Shimadzu, Kyoto, Japan). For analytical purposes, a Kromasil 100-5 C18 $(250 \times 4.6 \mathrm{~mm}, 5 \mu \mathrm{m})$ column was used. The mobile phase was composed of water containing $0.1 \%$ formic acid (A) and methanol (B), and the gradient of eluent $B$ started at $5 \%$ and gradually increased to $90 \%$ over $90 \mathrm{~min}$ at a flow rate of $1 \mathrm{~mL} / \mathrm{min}$. The MS conditions refer to Niu et al. [48].

Standards of hypocrellin A (HA), hypocrellin B (HB) and shiraiachrome A (SA), purity $\geq 98 \%$ (HPLC), were purchased from Biopurify Phytochemicals Ltd. Standards of elsinochrome A (EA), elsinochrome B (EB) and elsinochrome C (EC), purity $\geq 98 \%$ (HPLC), were purchased from Hangzhou Viablife Biotech CO., Ltd. An Agilent 1200 HPLC-DAD system was used to analyze the perylenequinonoid compounds, which was equipped with a Kromasil 100-5 C18 $(250 \times 4.6 \mathrm{~mm}, 5 \mu \mathrm{m})$ column. The column was maintained at $35^{\circ} \mathrm{C}$. The mobile phase was composed of water containing $0.1 \%$ phosphoric acid (A) and methanol (B) at a flow rate of $1 \mathrm{~mL} / \mathrm{min}$ with the following gradient: $0-10 \mathrm{~min}, 60 \% \mathrm{~B}$; 10-15 min, 60-70\% B; 15-25 min, 70\% B; 25-45 min, 70-75\% B; 45-60 min, 75-100\% B; $60-80 \mathrm{~min}, 100 \% \mathrm{~B}$. The UV-Vis spectrum was recorded at $200-800 \mathrm{~nm}$. All sample solutions were filtered by a membrane $(0.22 \mu \mathrm{m})$ prior to analysis. For each sample, the injection volume was $10 \mu \mathrm{L}$, and the external standard method [29] was applied for the quantitative analysis, using a detection wavelength of $460 \mathrm{~nm}$.

\section{Results}

\subsection{Phylogeny}

The multi-locus phylogenetic analysis included 68 ingroup samples, and used Pleospora herbarum (CBS 191.86) as outgroup. The dataset of five loci comprised 3831 characters including the alignment gaps, of which 622 characters were parsimony-informative, 172 parsimony-uninformative and 3037 constant. A best scoring RAxML tree is shown in Figure 2, the maximum parsimony and Bayesian tree confirmed the tree topology obtained with maximum likelihood.

The results showed that among 14 strains isolated in this study, 10 strains were clustered together with endophyte group A as listed in Dai et al. [25], forming a highly supported clade $(\mathrm{BS}=100, \mathrm{BP}=100, \mathrm{PP}=1.00)$. The strains $\mathrm{CNUCC}$ 0122, $\mathrm{CNUCC} 0172$ and CNUCC MJ1 together with BJTC HOU999 were clustered in the clade of S. bambusicola. The strains CNUCC 1000 together with BJTC HOU1000 were clustered in the clade of R. bambusae.

\subsection{Taxonomy}

Based on phylogenetic analyses and morphological characteristics, a novel species belonging to a new genus was recognized in this study.

Shiraiaceae Y.X. Liu, Zi Y. Liu \& K.D. Hyde, Phytotaxa 103(1): 53 (2013). 
Pseudoshiraia conidialis C.L. Hou, Q.T. Wang \& P.F. Cannon gen. et sp. nov. (Figures 3 and 4).
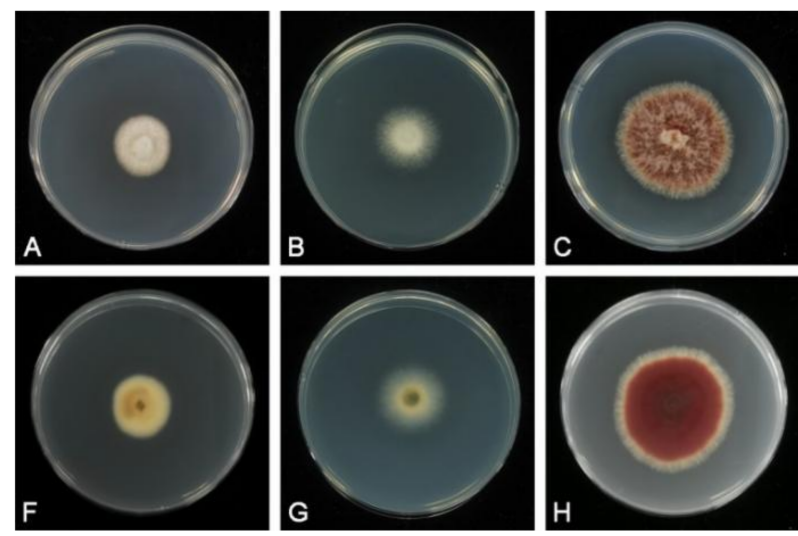
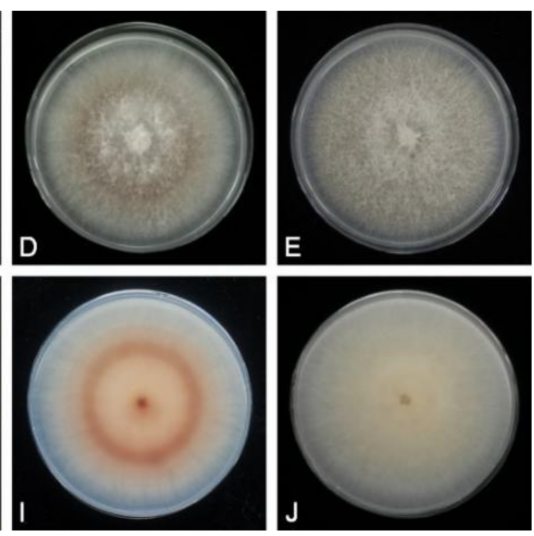

Figure 3. Colony morphology of cultures from Shiraia-like fungi. (A,F). Culture derived from a fruiting body of Shiraia bambusicola BJTC HOU999. (B,G). Culture derived from a fruiting body of Rubroshiraia bambusae BJTC HOU1000. (C,H). Pseudoshiraia conidialis CNUCC 1353PR. (D,I). Pseudoshiraia conidialis zzz816. (E,J) Pseudoshiraia conidialis JAP103846.

\section{MycoBank MB840497 (genus)}

MycoBank MB840566 (species)

Etymology. The name reveals that this species can produce hypocrellins like the species in genus Shiraia, but this species can only be found in an anamorphic stage at present.

Typification. CHINA, Yunnan province, on tissues of bamboos, May 2018, Q.T. Wang \& C.L. Hou (holotype CAF80003). Culture ex-type CNUCC 1353PR = CFCC 55715.

Diagnosis. Pseudoshiraia conidialis differs from Shiraia bambusicola by small, cylindrical or ellipsoidal conidia, without septa.

Description. Sexual morph unknown. On PDA: conidiomata erumpent through mycelium surface, brown, rough and hard, multi-loculate, $150-500 \times 175-625 \mu \mathrm{m}$ $(\bar{x}=375 \times 450 \mu \mathrm{m}, n=30)$. Conidiomatal wall of thick-walled angular cells, 5-8 $\mu \mathrm{m}$ in diam. Conidiogenous cells $4-5 \times 2.5-3 \mu \mathrm{m}$, enteroblastic, phialidic, hyaline, ampulliform, discrete, smooth. Conidia 1.5-2 $\times 2-3 \mu \mathrm{m}(\bar{x}=1.6 \times 2.4 \mu \mathrm{m}, n=30)$, hyaline, aseptate, cylindrical to ellipsoidal, smooth-and thin-walled.

Culture characteristics. Colonies on PDA 12-15 mm diam in $7 \mathrm{~d}$ (56-59 $\mathrm{mm}$ in $14 \mathrm{~d}$ ), with entire margin, surface very dark red (670a00), entirely covered with sparse white aerial mycelium and masses of pure (or mostly pure) orange (e6ac00) conidiomata. Reverse dark red (8a0022).

Note. The endophytic strains isolated from bamboos in this study and Shiraia-like endophytic strains which produce hypocrellins clustered together with high support values. This clade showed a close relationship with Shiraia bambusicola and Rubroshiraia bambusae. $S$. bambusicola is known to produce both sexual and asexual morphs, while R. bambusae only produces a sexual morph [25]. The conidia of $P$. conidialis and S. bambusicola are quite different. Those of $P$. conidialis are cylindrical or ellipsoidal, without septa, 1.5-2 $\times 2-3 \mu \mathrm{m}$ $(\bar{x}=1.6 \times 2.4 \mu \mathrm{m}, n=30)$; while those of $S$. bambusicola are fusiform and muriform with $15-18$ transverse septa, measuring $60-80 \times 19-25 \mu \mathrm{m}(\bar{x}=75.4 \times 23.1 \mu \mathrm{m}, n=20)$ [25]. Therefore, based on morphological characteristics and phylogenetic analysis, a new genus Pseudoshiraia may be established to accommodate the new species P. conidialis.

Other material examined. Guangxi Zhuang Autonomous Region, on seeds of Phyllostachys edulis (Carriere) J. Houzeau, Dec. 2006, C.L. Hou, culture zzz816. 

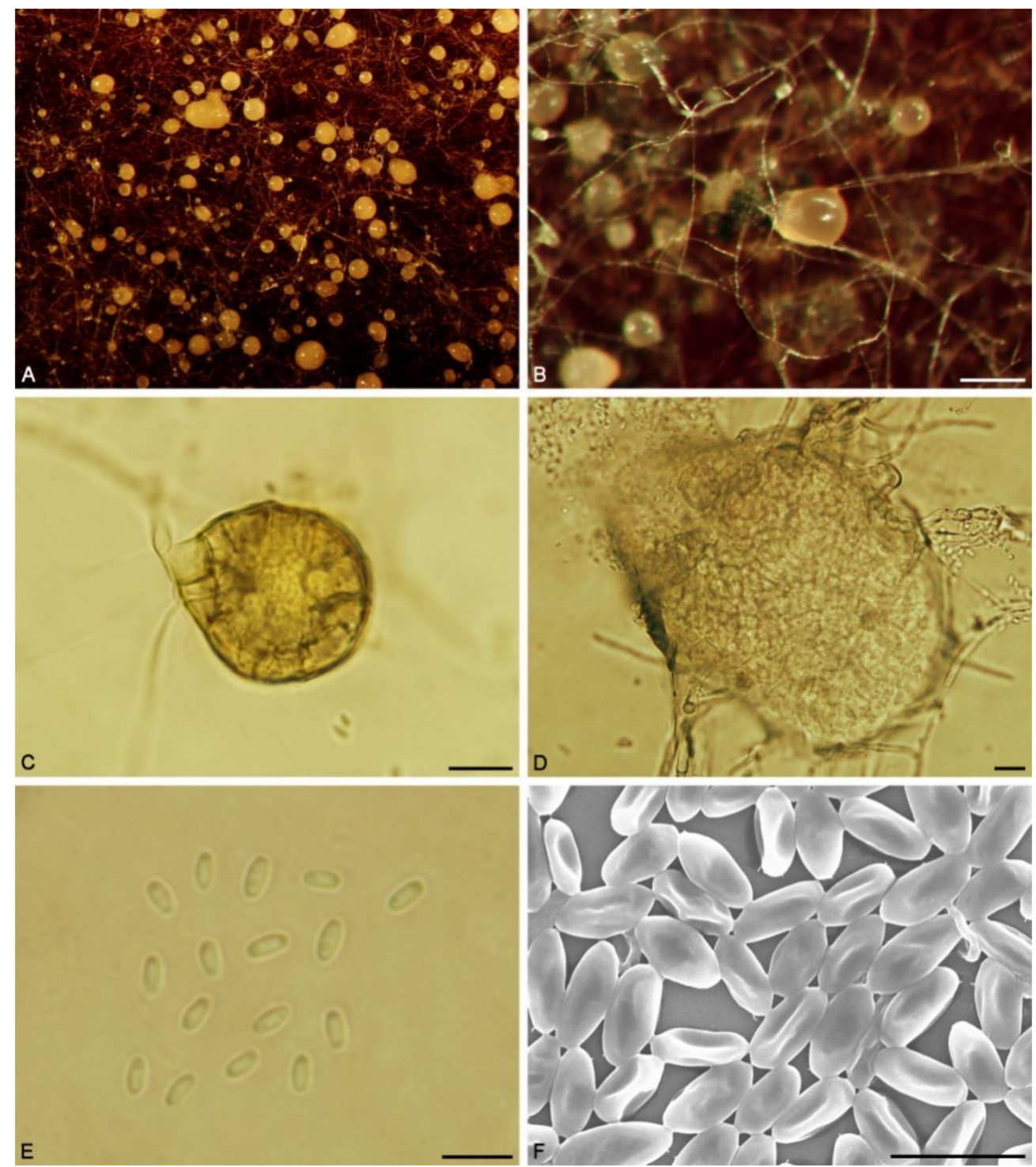

Figure 4. Pseudoshiraia conidialis (CNUCC 1353PR) (A). A mass of conidiomata. (B). Conidiomata on PDA. (C,D). Conidiomata. (E). Conidia. (F). SEM of conidia. Bars: B $=200 \mu \mathrm{m} ; \mathrm{C}-\mathrm{D}=10 \mu \mathrm{m} ; \mathrm{E}-\mathrm{F}=5 \mu \mathrm{m}$.

\subsection{Hypocrellin Identification and Production}

Six perylenequinonoid compounds were identified and quantified compared with UV-Vis spectra, MS spectra and retention time $\left(R_{t}\right)$ of standards (Supplementary Table S1). The HPLC chromatograms of extracts derived from fruit bodies of S. bambusicola BJTC HOU999 and R. bambusae BJTC HOU1000, and mycelia of S. bambusicola CNUCC MJ1, CNUCC 0122, CNUCC 0172, R. bambusae CNUCC 1000, P. conidialis CNUCC 1353PR, zzz816 and JAP103846 are all shown in Figure 5. The peaks at $40.3 \mathrm{~min}, 45.1 \mathrm{~min}, 36.6 \mathrm{~min}$, $38.3 \mathrm{~min}, 25.4 \mathrm{~min}$ and $21.7 \mathrm{~min}$ are indicated as HA, HB, SA, EA, EB and EC separately. For each sample, the content of each perylenequinonoid compound was calculated by the standard curves (Tables 3 and 4). No perylenequinonoid compounds appeared in extracts from mycelia of S. bambusicola CNUCC MJ1, CNUCC 0122, CNUCC 0172, R. bambusae CNUCC 1000 and P. conidialis JAP103846. Those from fruit bodies of S. bambusicola BJTC HOU999 and R. bambusae BJTC HOU1000 only produced hypocrellins, and that from R. bambusae BJTC HOU1000 $(65.89 \mathrm{mg} / \mathrm{g})$ produced a higher quantity of hypocrellins than S. bambusicola BJTC HOU999 $(10.39 \mathrm{mg} / \mathrm{g})$. It is noteworthy that the extracts from $P$. conidialis CNUCC 1353PR contained a large concentration of natural products, and both the total perylenequinonoid compound content $(1410.13 \mathrm{mg} / \mathrm{L})$ and that of the single 
compound HA $(677.11 \mathrm{mg} / \mathrm{L})$ showed a substantially higher quantity than any other known wild type strains in public papers [49-52].

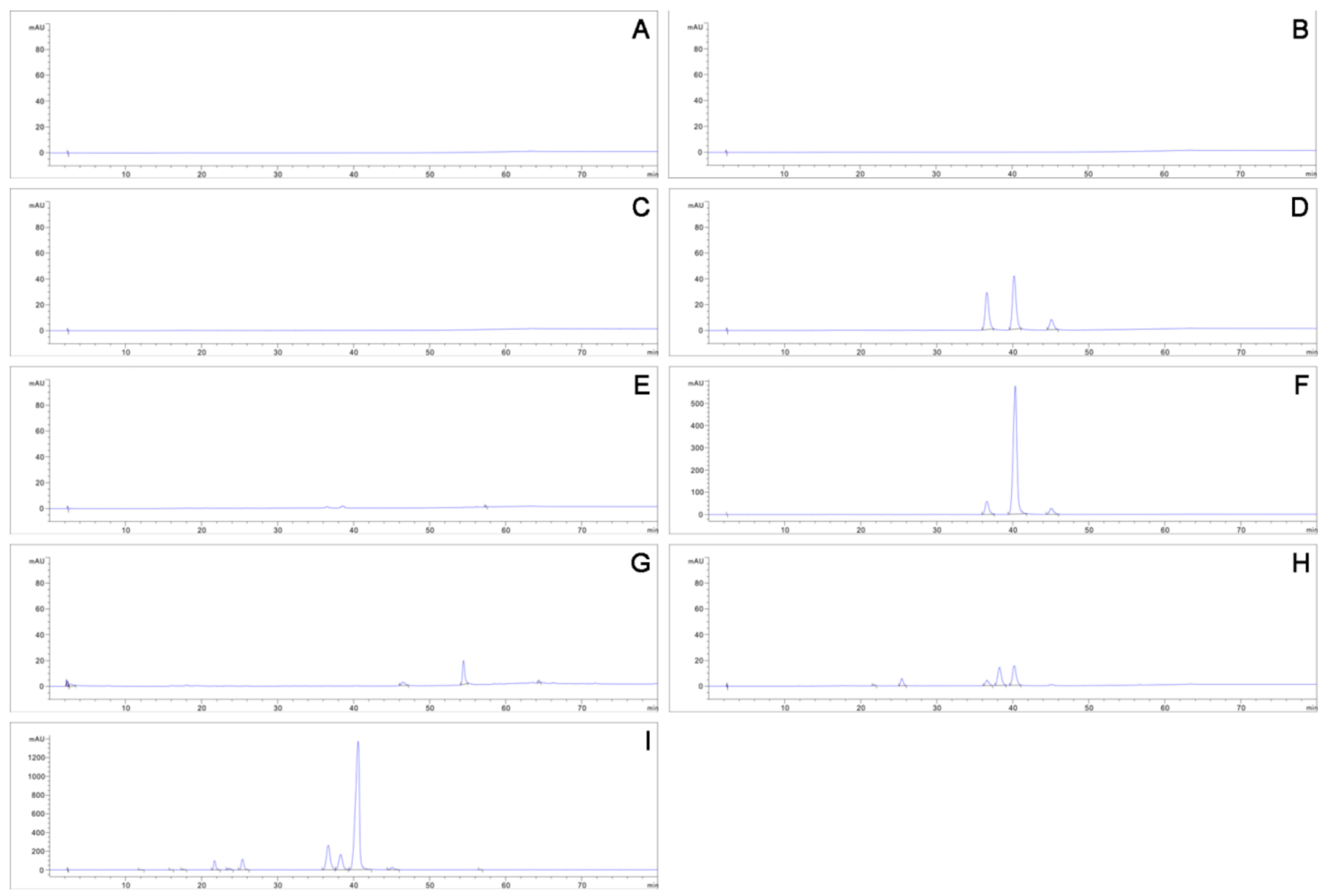

Figure 5. HPLC chromatograms of the samples. (A) mycelia of S. bambusicola CNUCC MJ1. (B) mycelia of S. bambusicola CNUCC 0122. (C) mycelia of S. bambusicola CNUCC 0172. (D) fruit body of S. bambusicola BJTC HOU999. (E) mycelia of R. bambusae CNUCC 1000. (F) fruit body of R. bambusae BJTC HOU1000. (G) mycelia of P. conidialis JAP103846. (H) mycelia of $P$. conidialis zzz816. (I) mycelia of $P$. conidialis CNUCC 1353PR.

Table 3. Content of each perylenequinonoid compounds (mg/g) of each fruiting body.

\begin{tabular}{cccccccc}
\hline Samples & HA & HB & SA & EA & EB & EC & Total Content \\
\hline $\begin{array}{c}\text { S. bambusicola BJTC } \\
\begin{array}{c}\text { HOU999 } \\
\text { R. bambusae BJTC } \\
\text { HOU1000 }\end{array}\end{array}$ & 3.60 & 1.80 & 4.99 & 0.00 & 0.00 & 0.00 & 10.39 \\
\hline
\end{tabular}

Table 4. Content of each perylenequinonoid compounds $(\mathrm{mg} / \mathrm{L})$ of each culture.

\begin{tabular}{cccccccc}
\hline Samples & HA & HB & SA & EA & EB & EC & Total Content \\
\hline zZZ816 & 84.86 & 1.71 & 41.11 & 226.48 & 7.19 & 0.86 & 362.22 \\
CNUCC 1353PR & 677.11 & 155.36 & 152.31 & 326.59 & 60.41 & 38.36 & 1410.13 \\
\hline
\end{tabular}

\section{Discussion}

In our previous study, a large number of strains were isolated from S. bambusicola and R. bambusae (Data not shown). However, hypocrellins were found only in fruiting bodies of S. bambusicola and R. bambusae, and cultured strains did not produce these chemicals (Figure 3). More recent studies have demonstrated that a few Shiraia-like endophytes isolated from bamboo tissues could produce hypocrellins, and even the strains isolated from the stromata of $S$. bambusicola could also produce hypocrellins [27,30,50,53-55]. But 
the taxonomic statuses of these strains were very confusing. Such as the strains Shiraia sp. SUPER H168, Shiraia sp. slf14, Shiraia sp. S9, S. bambusicola UV-62 and S. bambusicola $\mathrm{ZH}-5-1$ were isolated from bamboo tissues as endophytes or isolated from the stromata of $S$. bambusicola $[27,50,53,56,57]$. Although they were regarded as Shiraia spp., the strains Shiraia sp. SUPER H168, Shiraia sp. slf14 and Shiraia sp. S9 were clustered with Shiraia-like endophytes but not with Shiraia in the phylogenetic trees (Figure 2) [25,50]. Therefore, the taxonomic statuses of other strains like these need to be re-identified.

Morakotkarn et al. [26] and Dai et al. [25] isolated 22 Shiraia-like endophytic strains from bamboo tissues. Based on phylogenetic analysis, these strains were divided into two groups, one which could produce hypocrellins, and the other not. Among them, the group with hypocrellins was clustered with these known production strains (Figure 2), forming a highly supported clade. These belong to the newly described species Pseudoshiraia conidialis.

Unfortunately, cultures from most of the corresponding endophytes only had low production yield, and several attempts were made to increase hypocrellins production, such as addition of Triton X-100 surfactant to the submerged cultures [49], exposing cultures of Shiraia sp. to light at various wavelengths [58] or light/dark shift [59], or co-cultivation of Shiraia sp. with Pseudomonas fulva [50,60]. Our previous work [8] attempted to use gamma rays to mutate $P$. conidialis zzz816, boosting the HA production to increase to $414.9 \%$.

The conidium-producing and hypocrellin-generating strain CNUCC 1353PR was isolated and characterized in this study. To the best of our knowledge, hypocrellin production in $P$. conidialis CNUCC 1353 PR is significantly higher than other wild type $P$. conidialis strains in public [49-52]. Through comparative analysis of the metabolites of ascostromata and mycelia of S. bambusicola and R. bambusae, we discovered that HA, HB and SA only appeared in the ascostromata, but not in mycelia of cultured strains. In addition, the $P$. conidialis strains contain more diverse perylenequinonoid compounds, and in addition to HA, HB and SA, also produced EA, EB and EC; demonstrated by the four peaks $\left(\mathrm{R}_{\mathrm{t}} 12 \mathrm{~min}\right.$, $16 \mathrm{~min}, 17.5 \mathrm{~min}$ and $23.6 \mathrm{~min}$ ) in the HPLC chromatogram of the mycelia of $P$. conidialis CNUCC 1353PR (Figure 5I), and the UV-Vis spectra indicated that they all belonged to perylenequinones (Supplementary Figure S1). These results displayed that P. conidialis CNUCC 1353PR could be a potential industrial strain for perylenequinone production.

Other sources of perylenequinone production could be found. For example, strain MSX60519, isolated from dry leaf litter, was also found to produce hypocrellins [16], and Li et al. [61] explored an endolichenic strain, Phaeosphaeria sp. 20081120, which could produce HA, HB and other perylenequinones. Meng et al. [62] investigated metabolites produced by an endophytic fungus identified as Penicillium chrysogenum isolated from Fagonia cretica, and also found hypocrellins. However, these strains did not cluster with Shiraiaceae (Figure 2). Although the species of other family may also produce hypocrellins, further studies and verification are needed.

\section{Conclusions}

In this study, a new genus Pseudoshiraia in Shiraceae was established, and a series of species with high output of hypocrellins were exploited for the first time. Furthermore $P$. conidialis CNUCC 1353PR contains multiple types of perylenequinones, not only hypocrellins but also elsinochromes.

Supplementary Materials: The following are available online at https:/ / www.mdpi.com/article/10 .3390/jof7070563/s1, Table S1: HPLC-DAD-MS data of perylenequinonoid compounds in this study, Figure S1: UV-Vis spectra of HA (A), HB (B), SA (C), EA (D), EB (E), EC (F), the peak in12 min (G), $16 \min (\mathrm{H}), 17.5 \mathrm{~min}(\mathrm{I})$ and $23.6 \mathrm{~min}(\mathrm{~J})$.

Author Contributions: Conceptualization, X.T., Q.-T.W., X.-Y.S. and C.-L.H.; data curation, X.T. and Q.-T.W.; formal analysis, X.T. and Q.-T.W.; funding acquisition, C.-L.H.; methodology, X.T., Q.-T.W., X.-Y.S. and C.-L.H.; project administration, X.-Y.S. and C.-L.H.; resources, X.T., Q.-T.W. and C.-L.H.; supervision, X.-Y.S. and C.-L.H.; writing-original draft, X.T. and Q.-T.W.; writing-review and editing, X.T., Q.-T.W., X.-Y.S., C.-L.H. and P.F.C. All authors have read and agreed to the published version of the manuscript. 
Funding: This study was supported by the National Natural Science Foundation of China (no. 31870629 and 31470145).

Institutional Review Board Statement: Not applicable.

Informed Consent Statement: Not applicable.

Data Availability Statement: Not submitted yet. The sequencing data is prepared to submit to GenBank, the combined alignment and phylogenetic tree are prepared to submit to TreeBASE.

Conflicts of Interest: The authors declare no conflict of interest.

\section{References}

1. Wan, X.Y.; Chen, Y.T. Hypocrellin A-A new drug for photochemotherapy. Chinese Sci. Bull. 1981, 26, 1040-1042.

2. Ma, J.S.; Yan, F.; Wang, C.Q.; An, J.Y. Hypocrellin-A sensitized photoxidation of bilirubin. Photochem. Photobiol. 1989, 50, 827-830. [CrossRef] [PubMed]

3. Ma, L.; Tai, H.; Li, C.; Zhang, Y.; Wang, Z.H.; Ji, W.Z. Photodynamic inhibitory effects of three perylenequinones on human colorectal carcinoma cell line and primate embryonic stem cell line. World J. Gastroenterol. 2003, 9, 485-490. [CrossRef] [PubMed]

4. Ma, G.; Khan, S.I.; Jacob, M.R.; Tekwani, B.L.; Li, Z.; Pasco, D.S.; Walker, L.A.; Khan, I.A. Antimicrobial and antileishmanial activities of hypocrellins A and B. Antimicrob. Agents Chemother. 2004, 48, 4450-4452. [CrossRef]

5. Deininger, M.H.; Weinschenk, T.; Morgalla, M.H.; Meyermann, R.; Schluesener, H.J. Release of regulators of angiogenesis following hypocrellin-A and -B photodynamic therapy of human brain tumor cells. Biochem. Bioph. Res. Commun. 2002, 298, 520-530. [CrossRef]

6. Ali, S.M.; Chee, S.K.; Yuen, G.Y.; Olivo, M. Hypericin and hypocrellin induced apoptosis in human mucosal carcinoma cells. J. Photoch. Photobiol. B 2001, 65, 59-73. [CrossRef]

7. Hudson, J.B.; Zhou, J.; Chen, J.; Harris, L.; Yip, L.; Towers, G.H.N. Hypocrellin, from Hypocrella bambuase, is phototoxic to human immunodeficiency virus. Photochem. Photobiol. 1994, 60, 253-255. [CrossRef]

8. Liu, X.Y.; Shen, X.Y.; Fan, L.; Gao, J.; Hou, C.L. High-efficiency biosynthesis of hypocrellin A in Shiraia sp. using gamma-ray mutagenesis. Appl. Microbiol. Biotechnol. 2016, 100, 4875-4883. [CrossRef]

9. Guo, L.Y.; Yan, S.Z.; Tao, X.; Yang, Q.; Li, Q.; Wang, T.S.; Yu, S.Q.; Chen, S.L. Evaluation of hypocrellin A-loaded lipase sensitive polymer micelles for intervening methicillin-resistant Staphylococcus Aureus antibiotic-resistant bacterial infection. Mater. Sci. Eng. C 2020, 106, 110230. [CrossRef]

10. Wang, H.; Jia, Q.; Liu, W.; Nan, F.; Zheng, X.; Ding, Y.; Ren, H.; Wu, J.; Ge, J. Hypocrellin Derivative-Loaded Calcium Phosphate Nanorods as NIR Light-Triggered Phototheranostic Agents with Enhanced Tumor Accumulation for Cancer Therapy. ChemMedChem 2020, 15, 177-181. [CrossRef]

11. Zheng, X.; Liu, W.; Ge, J.; Jia, Q.; Nan, F.; Ding, Y.; Wu, J.; Zhang, W.; Lee, C.S.; Wang, P. Biodegradable natural productbased nanoparticles for near-infrared fluorescence imaging-guided sonodynamic therapy. ACS Appl. Mater. Interfaces 2019, 11, 18178-18185. [CrossRef]

12. Zhang, C.; Wu, J.; Liu, W.; Zheng, X.; Zhang, W.; Lee, C.S.; Wang, P. Hypocrellin-Based Multifunctional Phototheranostic Agent for NIR-Triggered Targeted Chemo/Photodynamic/Photothermal Synergistic Therapy against Glioblastoma. ACS Appl. Bio Mater. 2020, 3, 3817-3826. [CrossRef]

13. Shen, X.Y.; Zheng, D.Q.; Gao, J.; Hou, C.L. Isolation and evaluation of endophytic fungi with antimicrobial ability from Phyllostachys edulis. Bangl. J. Pharmacol. 2012, 7, 249-257. [CrossRef]

14. Su, Y.J.; Rao, S.Q.; Cai, Y.J.; Yang, Y.J. Preparation and characterization of the inclusion complex of hypocrellin A with hydroxypropyl- $\beta$-cyclodextrin. Eur. Food Res. Technol. 2010, 231, 781-788. [CrossRef]

15. Su, Y.J.; Si, S.H.; Qiao, L.W.; Cai, Y.J.; Xu, Z.M.; Yang, Y.J. The effect of a hypocrellin A enriched diet on egg yolk quality and hypocrellin A distributions in the meat of laying hens. Eur. Food Res. Technol. 2011, 232, 935-940. [CrossRef]

16. Al Subeh, Z.Y.; Raja, H.A.; Monro, S.; Flores-Bocanegra, L.; El-Elimat, T.; Pearce, C.J.; McFarland, S.A.; Oberlies, N.H. Enhanced production and anticancer properties of photoactivated perylenequinones. J. Nat. Prod. 2020, 83, 2490-2500. [CrossRef]

17. Chen, W.X.; Cheng, Y.T.; Wan, X.Y.; Friedrichs, E.; Puff, H.; Breitmaier, E. Die Struktur des Hypocrellins und seines Photooxidationsproduktes Peroxyhypocrellin. Liebigs Ann. Chem. 1981, 1880-1885.

18. Wan, X.Y.; Zhang, W.L.; Wang, Q.F. Isolation and identification of hypocrellin B from Hypocrella bambusae. J. Yunnan Univ. 1985, 4, 461-463.

19. Zhang, M.H.; Chen, S.; An, J.Y.; Jiang, L.J. Separation and identification of hypocrellin B and fatty acids as ingredients in Hypocrella bambusae (B. et Br.) Sacc. Chin. Sci. Bull. 1989, 34, 1008-1014.

20. Liu, B. Chinese Medicinal Fungi, 2nd ed.; Shanxi People's Publishing House: Taiyuan, China, 1978; pp. 9-11.

21. Wu, H.; Lao, X.F.; Wang, Q.W.; Lu, R.R.; Shen, C.; Zhang, F.; Liu, M.; Jia, L. The shiraiachromes: Novel fungal perylenequinone pigments from Shiraia bambusicola. J. Nat. Prod. 1989, 52, 948-951. [CrossRef]

22. Kishi, T.; Tahara, S.; Taniguchi, N.; Tsuda, M.; Tanaka, C.; Takahashi, S. New perylenequinones from Shiraia bambusicola. Planta Med. 1991, 57, 376-379. [CrossRef] 
23. Fang, L.Z.; Qing, C.; Shao, H.J.; Yang, Y.D.; Dong, Z.J.; Wang, F.; Zhao, W.; Yang, W.Q.; Liu, J.K. Hypocrellin D, a cytotoxic fungal pigment from fruiting bodies of the ascomycete Shiraia bambusicola. J. Antibiot. 2006, 59, 351-354. [CrossRef]

24. Liu, Y.X.; Hyde, K.D.; Ariyawansa, H.A.; Li, W.J.; Zhou, D.Q.; Yang, Y.L.; Chen, Y.M.; Liu, Z.Y. Shiraiaceae, new family of Pleosporales (Dothideomycetes, Ascomycota). Phytotaxa 2013, 103, 51-60. [CrossRef]

25. Dai, D.Q.; Wijayawardene, N.N.; Tang, L.Z.; Liu, C.; Han, L.H.; Chu, H.L.; Wang, H.B.; Liao, C.F.; Yang, E.F.; Xu, R.F.; et al Rubroshiraia gen. nov., a second hypocrellin-producing genus in Shiraiaceae (Pleosporales). MycoKeys 2019, 58, 1-26. [CrossRef]

26. Morakotkarn, D.; Kawasaki, H.; Tanaka, K.; Okane, I.; Seki, T. Taxonomic characterization of Shiraia-like fungi isolated from bamboos in Japan. Mycoscience 2008, 49, 258-265. [CrossRef]

27. Liang, X.H.; Cai, Y.J.; Liao, X.R.; Wu, K.; Wang, L.; Zhang, D.B.; Meng, Q. Isolation and identification of a new hypocrellin A-producing strain Shiraia sp. SUPER-H168. Microbiol. Res. 2009, 164, 9-17. [CrossRef]

28. Zhang, M.; Pang, W.; Wang, J. Effect of oxidative stress on hypocrellin A yield in submerged cultures of endophytic Shiraia sp. A8. Planta Med. 2014, 80, P1N2. [CrossRef]

29. Tong, Z.W.; Mao, L.; Liang, H.; Zhang, Z.; Wang, Y.; Yan, R.; Zhu, D. Simultaneous Determination of Six Perylenequinones in Shiraiaia sp. Slf14 by HPLC. J. Liq. Chromatogr. Relat. Technol. 2017, 40, 536-540. [CrossRef]

30. Shen, X.Y.; Cheng, Y.L.; Cai, C.J.; Fan, L.; Gao, J.; Hou, C.L. Diversity and Antimicrobial Activity of Culturable Endophytic Fungi Isolated from Moso Bamboo Seeds. PLoS ONE 2014, 9, e95838. [CrossRef]

31. Zhou, Y.K.; Shen, X.Y.; Hou, C.L. Diversity and antimicrobial activity of culturable fungi from fishscale bamboo (Phyllostachys Heteroclada) in China. World J. Microbiol. Biotechnol. 2017, 33, 104. [CrossRef]

32. Liu, F.; Hu, D.M.; Cai, L. Conlarium duplumascospora gen. et. sp. nov. and Jobellisia guangdongensis sp. nov. from freshwater habitats in China. Mycologia 2012, 104, 1178-1186. [CrossRef] [PubMed]

33. Gardes, M.; Bruns, T.D. ITS primers with enhanced specificity for basidiomycetes-application to the identification of mycorrhizae and rusts. Mol. Ecol. 1993, 2, 113-118. [CrossRef] [PubMed]

34. White, T.J.; Bruns, T.D.; Lee, S.; Taylor, J. Amplification and Direct Sequencing of Fungal Ribosomal RNA Genes for Phylogenetics. In PCR Protocols: A Guide to Methods and Applications; Innis, M.A., Gelfand, D.H., Sninsky, J.J., Eds.; Academic Press: New York, NY, USA, 1990; pp. 315-322.

35. Vilgalys, R.; Hester, M. Rapid genetic identification and mapping of enzymatically amplified ribosomal DNA from several Cryptococcus species. J. Bacteriol. 1990, 172, 4238-4246. [CrossRef] [PubMed]

36. Rehner, S.A.; Buckley, E.A. Beauveria phylogeny inferred from nuclear ITS and EF1- $\alpha$ sequences: Evidence for cryptic diversification and links to Cordyceps teleomorphs. Mycologia 2005, 97, 84-98. [CrossRef] [PubMed]

37. Liu, Y.J.; Whelen, S.; Hall, B.D. Phylogenetic relationships among ascomycetes: Evidence from an RNA polymerse II subunit. Mol. Biol. Evol. 1999, 16, 1799-1808. [CrossRef] [PubMed]

38. Ariyawans, H.A.; Tsai, I.; Thambugala, K.M.; Chuang, W.Y.; Lin, S.R.; Hozzein, W.N.; Cheewangkoon, R. Species diversity of Pleosporalean taxa associated with Camellia sinensis (L.) Kuntze in Taiwan. Sci. Rep. UK 2020, 10, 12762. [CrossRef]

39. Farris, J.S.; Källersjö, M.; Kluge, A.G.; Bult, C. Testing significance of incongruence. Cladistics-the international. J. Willi Hennig Soc. 1994, 10, 315-319. [CrossRef]

40. Huelsenbeck, J.P.; Hillis, D.M.; Jones, R. Parametric Bootstrapping in Molecular Phylogenetics: Applications and Performance. In Molecular Zoology: Advances, Strategies and Protocols; Ferraris, J.D., Palumbi, S.R., Eds.; Wiley: New York, NY, USA, 1996; pp. 19-45.

41. Swofford, D.L. Phylogenetic Analysis Using Parsimony ( ${ }^{*}$ and Other Methods), Version 4.0b10; Sinauer Associates: Sunderland, MA, USA, 2002.

42. Ronquist, F.; Huelsenbeck, J.P. MrBayes 3: Bayesian phylogenetic inference under mixed models. Bioinformatics 2003, 19, 1572-1574. [CrossRef]

43. Nylander, J.A.A. MrModeltest v2; Program Distributed by the Author; Evolutionary Biology Centre, Uppsala University: Uppsala, Sweden, 2004.

44. Stamatakis, A.; Ludwig, T.; Meier, H. RAxML-III: A fast program for maximum likelihood-based inference of large phylogenetic trees. Bioinformatics 2005, 21, 456-463. [CrossRef]

45. Stamatakis, A. RAxML-VI-HPC: Maximum likelihoodbased phylogenetic analyses with thousands of taxa and mixed models. Bioinformatics 2006, 22, 2688-2690. [CrossRef]

46. Stamatakis, A. RAxML version 8: A tool for phylogenetic analysis and post-analysis of large phylogenies. Bioinformatics 2014, 30, 1312-1313. [CrossRef]

47. Page, R.D.M. TreeView: An application to display phylogenetic trees on personal computers. Compu. Appl. Biosci. 1996, 12, 357-358.

48. Niu, Y.; Wang, H.; Tong, X.; Li, X.; Guo, N.; Zhang, X.; Luo, Y.; Gao, Y.; He, T.; Lin, Z.; et al. Development of an on-line analytical platform to screen haptens in shuxuening injection based on high-performance liquid chromatography coupled with ion-trap multistage mass spectrometry and human serum albumin fluorescence detection. J. Chromatogr. A 2019, 1598, 232-241. [CrossRef]

49. Cai, Y.; Liao, X.; Liang, X.; Ding, Y.; Sun, J.; Zhang, D. Induction of hypocrellin production by Triton X-100 under submerged fermentation with Shiraia sp. SUPER-H168. New Biotechnol. 2011, 28, 588-592. [CrossRef]

50. Ma, Y.J.; Zheng, L.P.; Wang, J.W. Bacteria associated with Shiraia fruiting bodies influence fungal production of hypocrellin A. Front. Microbiol. 2019, 10, 2023. [CrossRef] 
51. Li, X.P.; Ma, Y.J.; Wang, J.W. Adding bamboo charcoal powder to Shiraia bambusicola preculture improves hypocrellin A production. Sustain. Chem. Pharm. 2019, 14, 100191. [CrossRef]

52. Li, X.P.; Wang, Y.; Ma, Y.J.; Wang, J.W.; Zheng, L.P. Nitric Oxide and Hydrogen Peroxide Signaling in Extractive Shiraia Fermentation by Triton X-100 for Hypocrellin A Production. Int. J. Mol. Sci. 2020, 21, 882. [CrossRef]

53. Hu, F.; Li, R.X.; Li, C.R.; Fan, M.Z. Hypocrellins produced by liquid fermentation of an anamorphic strain from Shiraia bambusicola. J. Biol. 2008, 25, 43-47.

54. Du, W.; Liang, Z.; Zou, X.; Han, Y.; Liang, J.; Yu, J.; Chen, W.; Wang, Y.; Sun, C. Effects of microbial elicitor on production of hypocrellin by Shiraia bambusicola. Folia Microbiol. 2013, 58, 283-289. [CrossRef]

55. Sun, C.X.; Ma, Y.J.; Wang, J.W. Enhanced production of hypocrellin A by ultrasound stimulation in submerged cultures of Shiraia bambusicola. Ultrason. Sonochem. 2017, 38, 214-224. [CrossRef]

56. Yang, H.; Xiao, C.; Ma, W.; He, G. The production of hypocrellin colorants by submerged cultivation of the medicinal fungus Shiraia bambusicola. Dyes Pigments 2009, 82, 142-146. [CrossRef]

57. Zhu, D.; Wang, J.; Zeng, Q.; Zhang, Z.; Yan, R. A novel endophytic Huperzine A-producing fungus, Shiraia sp. Slf14, isolated from Huperzia serrata. J. Appl. Microbiol. 2010, 109, 1469-1478. [CrossRef] [PubMed]

58. Gao, R.; Xu, Z.; Deng, H.; Guan, Z.; Liao, X.; Zhao, Y.; Zheng, X.; Cai, Y. Influences of light on growth, reproduction and hypocrellin production by Shiraia sp. SUPER-H168. Arch. Microbiol. 2018, 200, 1217-1225. [CrossRef]

59. Sun, C.X.; Ma, Y.J.; Wang, J.W. Improved hypocrellin A production in Shiraia bambusicola by light-dark shift. J. Photoch. Photobio. B Biol. 2018, 182, 100-107. [CrossRef]

60. Ma, Y.J.; Zheng, L.P.; Wang, J.W. Inducing perylenequinone production from a bambusicolous fungus Shiraia sp. S9 through co-culture with a fruiting body-associated bacterium Pseudomonas Fulva SB1. Microb. Cell Fact. 2019, 18, 121. [CrossRef]

61. Li, G.; Wang, H.; Zhu, R.; Sun, L.; Wang, L.; Li, M.; Li, Y.; Liu, Y.; Zhao, Z.; Lou, H. Phaeosphaerins A-F, Cytotoxic Perylenequinones from an Endolichenic Fungus, Phaeosphaeria sp. J. Nat. Prod. 2012, 75, 142-147. [CrossRef]

62. Meng, L.; Sun, P.; Tang, H.; Li, L.; Draeger, S.; Schulz, B.; Krohn, K.; Hussain, H.; Zhan, W.; Yi, Y. Endophytic fungus Penicillium chrysogenum, a new source of hypocrellins. Biochem. Syst. Ecol. 2011, 39, 163-165. [CrossRef] 